\title{
Reliability of Fingerprint Verification in Ghana
}

\author{
Osman Yakubu \\ Garden City University College \\ Department of Computer Science \\ Kenyasi, Kumasi, Ghana
}

\author{
Osei Adjei \\ Garden City University College \\ Department of Computer Science \\ Kenyasi, Kumasi, Ghana
}

\begin{abstract}
Biometric recognition refers to the automatic recognition of individuals based on their physiological and/or behavioral characteristics. It is used to confirm an individual's identity rather than using an identification card. Unique identifiers of humans include fingerprints, hand geometry, earlobe geometry and retina. Fingerprint verification is one of the most reliable personal identification methods. The performance of Automatic fingerprint identification systems relies heavily on the quality of the captured fingerprint images. Automatic Fingerprint identification systems are currently being implemented in Ghana. In the 2012 elections, fingerprint biometric verification was implemented and the opposition went to court challenging the results. One of their petitions is that some voters did not go through biometric verification, but the electoral commission argued that even though the verification machines rejected them, their names were in the electoral register and they had identification cards. This research studied categories of workers who do not protect their fingers while at work and established that quite a number of them cannot be verified with fingerprint methods successfully because they had poor fingerprint images. A multimodal approach is proposed where multiple traits can be used, but if it is found to be expensive parties should develop a framework to enable those who cannot be verified due to poor fingerprint images to vote.
\end{abstract}

\section{Keywords}

Biometrics, fingerprint, verification, multimodal, election, petition, multimodal

\section{INTRODUCTION}

Biometric verification is any means by which a person can be distinctively identified by assessing one or more distinguishing biological traits. Unique identifiers of humans include fingerprints, hand geometry, earlobe geometry, retina, iris patterns, DNA, and gaits. Fingerprint as a biometric verification has been in existence for a longtime [1]. Iris-pattern and retinapattern authentication methods are already employed in some bank automatic teller machines. Facial-recognition technology has been used by law enforcement to pick out individuals in large crowds with considerable reliability [2]. Hand geometry is being used in industry to provide physical access to buildings. Earlobe geometry has been used to disprove the identity of individuals who claim to be someone they are not (identity theft). In Biometric verification, a record of a person's distinguishing feature is captured and kept in a database. Later on, when identification verification is required, a new record is captured and compared with the previous record in the database. If the data in the new record matches that in the database record, the person's identity is confirmed.

Among all the biometric indicators, fingerprints have one of the highest levels of reliability and have been extensively used by forensic experts in criminal investigations [3]. A fingerprint is the pattern of ridges and valleys on the surface of the finger [4], they are graphical flow-like ridges present on human fingers. They have been widely used in personal identification for several centuries [4]. Each individual has unique fingerprints. The uniqueness of a fingerprint is exclusively determined by the local ridge characteristics and their relationships [4], the validity of their use has been well established. Inherently, using current technology fingerprint identification is much more reliable than other kinds of popular personal identification methods based on signature, face, and speech [5]. Although fingerprint verification is usually associated with criminal identification and police work, it has now become more popular in civilian applications such as access control, financial security, and verification of firearm purchasers and driver license applicants [3], [5].

In Ghana fingerprint verification was used to verify voters by the Electoral Commission before they cast their votes during the 2012 elections. In the face of advancing ICT trends and emerging challenges in manual voter registration, the Electoral Commission of Ghana took the bold decision to replace the current voters' register with a finger biometric register for subsequent elections [6]. It is also used by State agencies like the National Health Insurance Scheme and Government Ministries to register their members. Fingerprint verification is also used by employers in Time and Attendance Clocking Systems to track employee time and attendance.

Fingerprint identification is widely used in personal identification as it works well in most cases. However it is difficult to acquire unique fingerprint features i.e. minutiae for some class of persons such as manual laborers, elderly people, etc. [7]; [8]). Two samples of the same biometric characteristic from the same person (e.g., two impressions of a user's right index finger) are not exactly the same due to imperfect imaging conditions (e.g., sensor noise and dry fingers), changes in the user's physiological or behavioral characteristics (e.g., cuts and bruises on the finger), ambient conditions (e.g., temperature and humidity), and user's interaction with the sensor (e.g., finger placement) [2]. Majority of Ghanaians are engaged in the agricultural, mining and Timber sector, some are also hairdressers [9]. Most of these categories of workers work with their bare hands without protection such as gloves.

In this paper we will study the reliability of fingerprint verification in Ghana and suggest ways of improving verification so as to eliminate conflicts especially associated with verification before elections.

\section{AUTOMATIC FINGERPRINT VERIFICATION}

Automatic fingerprint identification systems (AFIS) are in great demand. Although significant progress has been made in designing automatic fingerprint identification systems over the past 30 years, a number of design factors (lack of reliable minutia 
extraction algorithms, difficulty in quantitatively defining a reliable match between fingerprint images, fingerprint classification, etc.) create bottlenecks in achieving the desired performance [4]. An automatic fingerprint identification system is concerned with some or all of the following issues:

- $\quad$ Fingerprint Acquisition: How to acquire fingerprint images and how to represent them in a proper format.

- Fingerprint Verification: To determine whether two fingerprints are from the same finger.

- $\quad$ Fingerprint Identification: To search for a query fingerprint in a database.

- Fingerprint Classification: To assign a given fingerprint to one of the pre-specified categories according to its geometric appearance [10].

A biometric system can be operated in verification mode and identification mode. A biometric system operating in the verification mode either accepts or rejects a user's claimed identity while a biometric system operating in the identification mode establishes the identity of the user without claimed identity information. The performance of a biometric system is specified in terms of false rejection rate or FRR which is the measure of the likelihood that the biometric security system will incorrectly reject an access attempt by an authorized user [11].

Automatic fingerprint matching depends on the comparison of local ridge characteristics and their relationships to make a personal identification [4]. The performance of minutiae extraction algorithm relies heavily on the quality of the input fingerprint images. In an ideal fingerprint image, ridges and valleys alternate and flow in a locally constant direction and minutiae are anomalies of ridges, i.e., ridge endings and ridge bifurcations. In such situations, the ridges can be easily detected and minutiae can be precisely located from the thinned ridges [12]. However, in practice, due to variations in impression conditions, ridge configuration, skin conditions a significant percentage of acquired fingerprint images are of poor quality. The ridge structures in poor-quality fingerprint images are not always well-defined and, hence, they cannot be correctly detected [13], [14].

\section{FINGERPRINT VERIFICATION IN GHANA}

A number of organizations both private and public use fingerprint verification in clocking machines to enable employees clock in and out for attendance recording. The Electoral Commission prior to Election 2012 compiled a biometric register of voters, the voters were required to be biometrically verified by fingerprint before they are allowed to vote. According to the Electoral Commission, the old method of registering voters did not have an in-built mechanism for detecting multiple registrations and therefore, there were instances where some unscrupulous individuals registered more than once. With biometric technology, the detection and removal of multiple registrations from the system will be made possible with relative ease thus, a more accurate and reliable register will be produced for Election 2012 and subsequent elections [6]. The Ghana Immigration service takes fingerprints in processing passports to applicants. This was started in 2009 when Ghana moved from both the handwritten and machine-readable to biometric [15].
The National Health Insurance Authority (NHIA) commenced a pilot project to register new subscribers onto the NHIS Biometrically. As part of its objectives, the exercise which began on Monday, June 17, 2013 is to ensure instant issuance of membership ID cards leading to improved card management. It is also to clean the membership database by using a Biometric Solution as a means of preventing duplicate records and implement an effective verification (authentication) system at the point of healthcare service delivery [16]. The increased interest in fingerprint biometrics in Ghana makes it imperative to find out its reliability and ways to improve it to ensure that there are no conflicts especially during the 2016 elections as the nation is set to use fingerprint biometric verification again. In Ghana it is believed that about $60 \%$ of the population is employed in the agricultural sector much of which is not mechanized.

As part of this research we decided to study how farmers, illegal miners, timber workers, students and hair dressers work and take a look at their fingers. We also decided to study mechanics working on cars, bicycles and vulcanizers. We would then sample these groups, capture their fingerprint data, verify them and analyse the data.

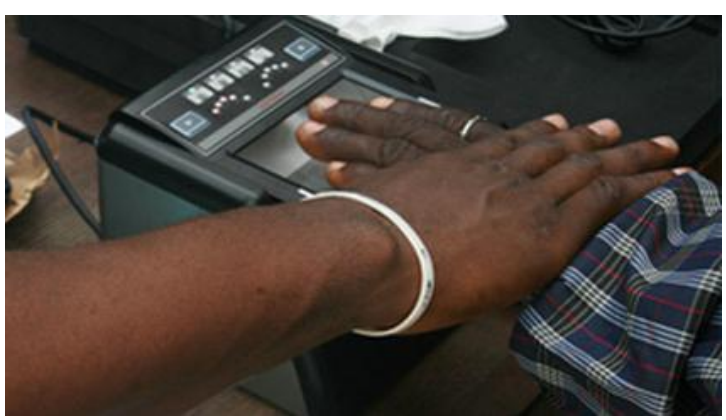

Figure 1. A voter going through fingerprint biometric registration [6]

\section{METHODOLOGY USED}

This research seeks to establish the reliability of fingerprint verification in Ghana given the background that most workers are manual labourers who do not protect their fingers. This could result in variations in impression conditions, ridge configuration, skin conditions so a significant percentage of acquired fingerprint images will be of poor quality. The ridge structures in poorquality fingerprint images are not always well-defined and, hence, they cannot be correctly detected [13].

We initially observed miners, hairdressers, timber workers, students, people washing clothes for a living and farmers, and market women numbering two thousand (2500). We wanted to find out how they protect their fingers while at work. Here we used descriptive research as its main purpose is to describe the state of affairs as it exists at present.

Table 1. Observation of Categories of workers

\begin{tabular}{|c|c|c|c|}
\hline Type of Jobs & No. Visited & $\begin{array}{c}\text { No. of Days } \\
\text { Observed }\end{array}$ & $\begin{array}{c}\text { Total No. of } \\
\text { Persons } \\
\text { observed }\end{array}$ \\
\hline $\begin{array}{c}\text { Hair dressing } \\
\text { Saloons }\end{array}$ & 8 & 2 & 48 \\
\hline Small Scale & 4 & 3 & 105 \\
\hline
\end{tabular}




\begin{tabular}{|c|c|c|c|}
\hline Miners & 4 & 4 & 2020 \\
\hline $\begin{array}{c}\text { Timber } \\
\text { Companies }\end{array}$ & 2 & 1 & 20 \\
\hline Laundry & 10 & 3 & 67 \\
\hline Farms & 4 & 3 & 240 \\
\hline Markets & & 3 & \\
\hline
\end{tabular}

Interviews were also conducted to understand how they work. In the second phase of the research, quantitative research was used since the underlying motive was to find out, with the state of their fingers the number that can be biometrically verified successfully. The fingerprints of the category of workers mentioned above were captured and verified. We started with the timber firms where all the four companies we visited had fingerprint clocking devices which recorded the attendance of workers. They fingerprint to clock in to show that they have reported for work and later clock out to show that they have closed.

Table 2. Day 1 Clocking by fingerprint in timber companies

\begin{tabular}{|c|c|c|c|}
\hline COMPANY & $\begin{array}{c}\text { NO. OF } \\
\text { EMPLOYEES }\end{array}$ & $\begin{array}{c}\text { NO OF } \\
\text { SUCCESSFUL } \\
\text { VERIFICATION }\end{array}$ & $\begin{array}{c}\text { NO. OF FAILED } \\
\text { VERIFICATION }\end{array}$ \\
\hline A & 1000 & 960 & 40 \\
\hline B & 1200 & 1127 & 73 \\
\hline C & 900 & 652 & 248 \\
\hline D & 146 & 139 & 7 \\
\hline
\end{tabular}

Table 3. Day 3 Clocking by fingerprint in timber companies

\begin{tabular}{|c|c|c|c|}
\hline COMPANY & $\begin{array}{c}\text { NO. OF } \\
\text { EMPLOYEES }\end{array}$ & $\begin{array}{c}\text { NO OF } \\
\text { SUCCESSFUL } \\
\text { VERIFICATION }\end{array}$ & $\begin{array}{c}\text { NO. OF FAILED } \\
\text { VERIFICATION }\end{array}$ \\
\hline $\mathrm{A}$ & 1000 & 920 & 80 \\
\hline $\mathrm{B}$ & 1200 & 1097 & 103 \\
\hline $\mathrm{C}$ & 903 & 810 & 93 \\
\hline $\mathrm{D}$ & 150 & 116 & 34 \\
\hline
\end{tabular}

Table 4. Day 4 Clocking by fingerprint in timber companies

\begin{tabular}{|c|c|c|c|}
\hline COMPANY & $\begin{array}{c}\text { NO. OF } \\
\text { EMPLOYEES }\end{array}$ & $\begin{array}{c}\text { NO OF } \\
\text { SUCCESSFUL } \\
\text { VERIFICATION }\end{array}$ & $\begin{array}{c}\text { NO. OF FAILED } \\
\text { VERIFICATION }\end{array}$ \\
\hline A & 970 & 923 & 47 \\
\hline B & 1207 & 987 & 220 \\
\hline C & 910 & 887 & 23 \\
\hline D & 141 & 125 & 16 \\
\hline
\end{tabular}

We encountered thirty (30) small scale miners, we developed a program to capture their fingerprints and subsequently verify them. Most of them refused to be captured because they thought we were going to expose them to the law enforcement agencies, however eleven of them volunteered to be captured and verified. They were verified using a clocking system, six (6) were verified successfully and five (5) were unsuccessful. Of the five (5) rejected they were asked to wash their hands very well with soap and after re-verification two (2) were accepted. The data of the three rejected were deleted and re-captured it, 1 was success and the two failed again.

Data on fifty (50) farmers were also captured, thirty one (31) were successfully verified. Seventy (70) hair dressers were also captured and sixty (60) of them were successfully verified and ten (10) were unsuccessful. One hundred (100) university students were captured and ninety eight (98) of them were successfully verified. The system used for capturing fingerprints and verification process is similar to the system shown in Figure 1.

\section{DATA PRESENTATION AND ANALYSIS}

As already mentioned the timber companies already had a clocking system so verification data was captured over three (3) days. Our observation was that of the number that failed during the verification some were successful the following day, those that failed for the two days had their data deleted and re-captured and some were able to clock for the next day. We observed the following scenarios;

1. Success in day 1 , failed in day 2 and success in day 3 ,

2. Success in day 1 , success in day 2 and failed in day 3 ,

3. Success in day 1 , failed in day 2 , and failed in day 3 ,

4. Failed in day 1 , success in day 2, success in day 3,

5. Failed in day 1 , failed in day 2 and success in day 3 .

Data is captured manually when there is a failed verification. The personnel in charge of the clocking system confirmed to us that if clocking fails continuously for 3 days the data on the person is deleted and re-captured, if it fails again then a card is issued to enable the person clock in. The hairdressers, miners and students were verified only once. We examined the hands of those who had difficulty being verified and realized that their fingerprint patterns were poor.

From this research as depicted in Table 2, Table 3 and Table 4 it became apparent that in biometric verification using fingerprint in Ghana, the success rate is $85 \%$. This largely is due to the fact that majority of manual workers do not protect their fingers and thus have poor fingerprint image quality. Out of the one hundred university students who were verified, only two failed which goes to emphasize that non manual workers have a higher probability of being verified successfully.

\section{NO FINGER VERIFICATION NO VOTING IN GHANA}

The Electoral Commission of Ghana introduced biometric registration of all eligible voters prior to the 2012 presidential and parliamentary elections. Electorates were to be biometrically verified by fingerprint before they would be allowed to vote [23]. The only exceptions were people without fingers. During the election it was alleged that some voters voted without being verified biometrically. The losing party petitioned the Supreme Court of Ghana on irregularities that occurred during the voting and notable among them was the fact that some people voted without being verified biometrically. The Supreme Court in its ruling established that voting was extended for another day due to 
the breakdown of verification equipments [20]. The opposition in their petition argued that even though voting was extended some people were not recognize by the verification machines but were allowed to vote contrary to the law which said 'no biometric verification no vote'. The Electoral Commissioner during the hearing argued that in case a chief who is well known in the area is not successful in being verified, the whole community knows him and can be allowed to vote provided he has been registered and holds an electoral card [17],[18]. This goes to emphasise the fact that there were people whose fingerprint were rejected by the verification machine.

In preparation for the 2016 general elections, political parties under the Institute of Economic Affairs (IEA) Ghana's Political Parties Program (GPPP) have called on the Electoral Commission (EC) to maintain the no verification no vote regulation [19]. This recommendation was made by the political parties as part of their proposals for electoral reforms, after their representatives attended workshops held for them by the IEA to discuss and review Ghana's electoral system with a view to proposing reforms as a result of the problems that occurred after the general Elections in 2012. The parties as part of their recommendations agreed that the no verification no vote regulation which was adopted in the 2012 general elections should be maintained and enforced in the 2016 elections [22]. This means that there must be authentication of fingerprints before a person is allowed to vote, the parties recommended. They however called on the EC to make every effort to improve upon the equipment and technology in order not to repeat the problem that characterized the 2012 general election with the use of the verification device [19].

It is clear that the political parties have acknowledged the fact that there were problems with verification but they are unanimous in their decision that the problems were caused by devices and technology [22] and they have ignored the fact that most of the rejections were caused by poor fingerprint images which is as a result of most people being manual workers who do not protect their fingers.

\section{RECOMMENDATION}

This research confirms to us that using only fingerprint verification in Ghana, eighty five $(85 \%)$ of the population will be successfully verified. A lot of vigilance shall be employed during the election in 2016 by party agents and members. Voters and interested parties will not understand if their names or names of their members are on the electoral register but cannot be verified by fingerprint even though they possess a valid voter ID card and possibly are known by people around. This could lead to violence in some electoral areas. Some of the limitations imposed by unimodal biometric systems can be overcome by using multiple biometric modalities (such as face and fingerprint of a person or multiple fingers of a person). Such systems, known as multimodal biometric systems [21], are expected to be more reliable. This will reduce the chances of complete rejection. If multi modal approach is expensive we recommend that the parties should be educated to know that when someone's verification is rejected, it doesn't mean that the technology or device is bad, it could mean that he or she has a problem with the quality of fingerprint image. They should therefore come up with a framework to deal with such issues.

\section{CONCLUSION}

In this paper we have proven that even though fingerprint verification is one of the most reliable personal identification methods, images captured for some category of people in Ghana is poor as a result of imperfect imaging conditions (e.g., sensor noise and dry fingers), changes in the user's physiological or behavioral characteristics (e.g., cuts and bruises on the finger), ambient conditions (e.g., temperature and humidity). Political parties in Ghana are still bent on using fingerprint biometric verification in the 2016 elections as was done in 2012. The parties should be aware that the number who could not be successfully verified was not as a result of the machines being faulty since others were successfully verified. It was because those who were not verified successfully had poor fingerprint images. We recommend that additional biometric traits such as face, earlobe or retina should be used, however if those in charge find it expensive then the fingerprint verification should be maintained so that the parties should develop a framework to enable a person who is unsuccessful in being verified to vote. This will result in an election that will be accepted devoid of any violence.

\section{REFERENCES}

[1] Kong, W.K., Zhang, D., Li, W. 2003 Palmprint feature extraction using 2-D Gabor filters, Pattern Recognition, (36), pp. 2339-2347.

[2] Jain, A.K., Ross, A., Prabhakar, S. 2004 An Introduction to Biometric Recognition, IEEE Transactions on Circuits And Systems For Video Technology, 14(1).

[3] Federal Bureau of Investigation 1984 The Science of Fingerprints: Classification and Uses, Washington, DC: Government Printing .

[4] Lee, H.C., Gaensslen, R.E. 1991 Advances in Fingerprint Technology, New York: Elsevier.

[5] Miller, B. 1994 'Vital Signs of Identity, IEEE Spectrum, 31(2), pp. 22-30.

[6] Bafo, A. 2011 Biometric Voter Registration: What You Should Know, Available at:http://ghanamagazine.com/factual/politics/biometricvoter-registration-what-you-shouldknow/\#.VEqTQPl_sTI (Accessed: 24th October 2014).

[7] Kumar, A., Shen, H.C., Jain, A.K. 2003 Personal Verification Using Palmprint and Hand Geometry Biometric, Springer-Verlag Berlin Heidelberg, LNCS(2688), pp. 668-678.

[8] Zhang, D. , Kong, W., You, J. , Wong, M. 2003 An Introduction to Biometric Recognition, IEEE Transactions On Pattern Analysis And Machine Intelligence, 25(9).

[9] Oppong-Anane, K. 2006 Country Pasture/Forage Resource Profiles, Available at:http://www.fao.org/ag/agp/AGPC/doc/Counprof/ghana/Gh ana.htm(Accessed: 4th November 2014).

[10] Jain. A., Hong, L., Bolle, R. 1997 On-Line Fingerprint Verification, IEEE Transactions On Pattern Analysis And Machine Intelligence, 19(4) 
[11] Jain, A.K., Prabhakar, S., Pankanti, S. 2000 Filterbank-Based Fingerprint Matching, IEEE Transactions On Image Processing, 9(5).

[12] Jain, A.K., Chen, Y., Demirkus, M. 2007 Pores and Ridges: High-Resolution Fingerprint Matching Using Level 3 Features,IEEE Transactions On Pattern Analysis And Machine Intelligence, 29(1).

[13] Hong, L., Wan, Y., Jain, A. 1998 Fingerprint Image Enhancement: Algorithm and Performance Evaluation, IEEE Transactions On Pattern Analysis And Machine Intelligence,, 20(8).

[14] Pankanti, S., Bolle, R.M. 2000 Biometrics: the future of identication, IEEE Computing, 33(2), pp. 46-49.

[15] Smith-Asante, E. 2014 Handwritten passports to be phased out in 2015, Available at: http://graphic.com.gh/news/general-news/23413handwritten-passports-to-be-phased-out-in2015.html(Accessed: 24th October 2014).

[16] NHIA 2013 Nhia Begins Biometric Registration And Instant Nhis Id Issuance, Available at:http://www.nhis.gov.gh/News/nhia-begins-biometricregistration-and-instant-nhis-idissuance\%232008\#.VEqbIfl_sTI (Accessed: 24th October 2014).

[17] Obour, O. K. 2013 Afari-Gyan admits double registration abroad, Available at: http://graphic.com.gh/news/politics/1814-afari-gyan- admits-double-registration-abroad.html (Accessed: 4th November 2014).

[18] Amoabin, K., 2013 Supreme Court Report, Available at:http://www.ghanaweb.com/GhanaHomePage/NewsArchiv elartikel.php?ID=276385 (Accessed: 4th November 2014).

[19] GNA 2014 EC urged to maintain no verification, no vote regulation, Available

at:http://www.ghananewsagency.org/politics/ec-urged-tomaintain-no-verification-no-vote-regulation78606 (Accessed: 26th November 2014).

[20] Supreme Court of Ghana 2013 Presidentional Election Petition, Accra: .

[21] Hong, L., Jain, A. K., Pankanti, S. 1999 Can multibiometrics improve performance ?, Proc. AutoID'99, (), pp. 59-64.

[22] Citifmonline 2014 Enforce 'no verification, no vote - IEA tells $E C$, Available at:http://www.citifmonline.com/2014/09/08/enforce-noverification-no-vote-iea-tells-ec/(Accessed: 27th November 2014).

[23] Jeorge Kingson 2012 Electoral Commission issues voting rules and says No Verification No Vote, Available at:http://www.africanelections.org/ghana/news_detail.php?n $w s=7048 \& t=$ Electoral $\% 20$ Commission $\% 20$ issues\%20voting $\% 20$ rules $\% 20$ and $\% 20$ says $\% 20 \% 3 \mathrm{Cb} \% 3$ ENo\%20Verificatio $n \% 20 N o \% 20$ Vote $\% 3 C / b \% 3 E$ (Accessed: 27th November 2014). 